\title{
Language Anxiety as a Major Impediment in Learning/Teaching English
}

\author{
Asha Choubey \\ (MJP Rohilkhand University, India) \\ doi:10.7575/aiac.alls.v.2n.2p.210
}

\begin{abstract}
Feelings of anxiety, apprehension and nervousness are commonly expressed by second/foreign language learners in learning to speak a second/foreign language. These feelings are considered to exert a potentially negative and detrimental effect on communication in the target language. I shall dwell on my own experience as a practitioner of ELT, and narrate the lessons that I learnt by trial and error method. I can divide my class in four distinct groups, (the Rural Hindi group /the Urban Hindi group/ the Classroom Exposure group and the Classroom \& Social Exposure group; RH/UH/CE/CSE) as they sit together in the Engineering class. Since I am more interested in the psychological aspect of language anxiety, I have used humour, relaxation and even distraction to therapeutic effects.
\end{abstract}

They say 'curiosity kills the cat'; and I repeat before my students: "Remember, anxiety kills the cat." But sadly most of the students in my (B.Tech.I) year class are anxious cats and every year helping them get the better of their anxiety before we begin with any learning is the biggest challenge I face. Needless to say, the same rule does not apply every year, so, every year and every batch of students leaves me more enriched due to the various experiments that I keep trying. I start by using informal chats with students to make them feel at ease. But a majorly Hindi-speaking state that Uttar Pradesh (See the note at the end of the chapter for further information on this language!) is, it is extremely difficult to help them continue with the same when very smoothly and smartly I switch to English. Even as I am using a mix of English with Hindi, I sense the discomfiture on some faces. This soon changes into stony looks and before I can even think of bringing them back to their informal chatty self, I see human faces turn into dead files before my eyes. All their eagerness to share their experiences with me dies down as soon as they see me cunningly switching to English. I leave the class hoping to devise some other means to help them rid their anxiety; I have tried sermonizing 
my students but to no avail. And all my anxious students build their own affective barriers making language learning tougher than it actually is.

Before I begin to narrate the story of my partial success I would do better to take a look at the English teacher's poor plight in an Engineering college/ institute where the first and foremost learning barrier is students' reluctance to learn something they consider inferior to their calling. Engineering students arrive freshly drunk from their school experience where art subjects are considered inferior to science subjects. The hangover continues through the first year and English courses are prescribed everywhere for the first year students only. Consequently, the poor English teacher is burdened with completely unwilling and even adversely charged learners. Also because Uttar Pradesh is a mainly Hindi- speaking state these students have little or poor orientation in English learning. Since the students behave like anxious kids, the English teacher's task becomes quite tough. This paper shall seek to explore the cause of anxiety and some practices that the researcher used successfully to cope with the frightening situation.

(I)

Brijesh Kumar, a diploma engineer cleared a state-level competitive exam to enroll into the second year of an engineering degree course at a Noida college. But finding himself unable to cope with the pressures of the English-medium instruction at the degree level, the 22-year-old committed suicide. His suicide note where he said that he could not cope with courses taught in English left me shocked as it did the whole country. A budding talent, who could crack a standard competitive exam would succumb to English, is something that raised many social, cultural, psychological doubts, but my doubt was purely psycholinguistic one. While his college director said: "What was the need to do a degree?" I only asked: "Why not?" He knew his subjects, so why should he not pursue a course of his choice? Again, the fact that the engineering degree course cannot be taught in Hindi is undeniable. But, why did a young man who could cope with tough engineering subjects, find himself helpless before English lessons? The only answer I could see was - anxiety, apprehension, fear, nervousness. Whatever name one gives it its symptoms are familiar: getting cold feet when asked to speak, a lack of confidence, tendency to avoid eye contact with the teacher lest she put a question.

Scholars like Elaine Horwitz (1986) believe that there is a definite connection between language anxiety and performance in the classroom. Around early 1980s, anxiety among 
students learning Math and Science was coming to be recognized as a matter of concern, but language anxiety was not acknowledged as language learning was supposed to be much easier than learning Science and Math. Horwitz taught Spanish and French at the University of Texas at Austin and was startled to see students having learning problems with their foreign language class.

Michael E. Geisler, Dean of language schools at Middlebury College says, "This [Language anxiety] tends to be a problem at college and university with a blanket language requirement." Since there is certainly a negative correlation between anxiety and achievement in language classes, the matter deserves serious concern. Many researchers (Aida, 1994; Bailey, 1983; Crookal and Oxford, 1991; Ely, 1986; Horwitz, Horwitz, \& Cope, 1986; Horwitz \& Young, 1991; Ganschow \& Sparks, 1996; Krashen, 1985; MacIntyre, 1995; MacIntyre \& Gardner, 1988, 1989, 1991; 1994; Muchnick \& Wolfe, 1982; Price, 1988, 1991; Schlesinger, 1995; Trylong, 1987; von Wörde, 1998; Young, 1990, 1991, 1992) have mentioned the negative impact of anxiety on learning a language even though there are only a few focused studies in this area. Gardner's socio-educational model of motivation considers situational anxiety as one of the important variables (Gardner, 1982). E. Horwitz (1986) sees a definite relation between language anxiety and achievement. She also devised an instrument FLCAS (Foreign Language Classroom Anxiety Scale) to measure this anxiety (Horwitz, 1986). Horwitz sees anxiety as a psychological construct, impeding language achievement. However, Sparks and Ganschow (1995) doubt it, and they think that anxiety is not the course but the result of poor achievement. They proposed LCDH (Linguistic Coding Differences Hypothesis) to question the correlation. Daly and Miller (1975) designed Second Language Writing Apprehension Test (SLWAT) which is more related with writing performance. Kitano (2001) comes up with some gender-segregated data showing that male students are more anxious than the female students while learning a second language. Also language anxiety may vary according to different language skills. A learner who is not good at reading may be a good speaker and vice versa, hence the anxiety levels experienced in various activities might vary accordingly.

Research focused mainly on a domain specific conceptualization of anxiety because the construct of test anxiety is not applicable to language learning situations. Horwitz's research focuses on classroom anxiety, and researchers also suggest that language learning contexts are particularly prone to anxiety arousal (Horwitz, Horwitz. and Cope, 1986; MacIntyre \& 
Gardner 1989; 1991, Price 1991; MacIntyre, 1995). Since anxiety can have serious impacts in terms of education postponement and the biggest challenge for the teachers remains to help the learners, it is imperative that psychological aspects in this context would be noted and given place of importance. It is also to be noted that such anxiety is typical not only in a foreign language learning environment but also equally in a second language learning context (Ellis, 1994; Krashen, 1988.).

Also important is the presence of a kind of facilitating anxiety throwing a daring challenge at the debilitating anxiety. According to research, "facilitating anxiety keeps learners alert to learning and eager to participate as they grow in the use of language and knowledge of content" (Hall, 2003). However, "Debilitating anxiety creates excessive worry and self-doubt and results in reduced participation and avoidance of language use" (Hall, 2003). According to Scovel, "Whereas facilitating anxiety produces positive effects on learners' performance, too much anxiety may cause a poor performance (1991, p. 105)."

(II)

So much for the past research, I shall now, focus on my own experience. I am one of those teachers who would not give up easily and also who would go to any extent to humour their learners. At any rate, I have to have results. Hence, I tried the traditional methods in my first year of teaching and also realized their futility. All my faith in the conventional teaching/learning environs having shattered, I was prepared for all kinds of experiments. I tried journal writing, though not with much success. I had problems with students from Hindi-medium schools as they were so shy and shut up, it was impossible to get them to open in their journals, too. A study conducted by Arnold (2000) explored a method of reducing anxiety about a listening examination involving two stages: relaxation and visualization. Arnold argues that "[t]raining of this nature might help free energy previously used in worrying for the much more productive cognitive operations of language processing" (p. 779). I had to think of devising ways to use relaxation and visualization, which was not coming easy.

Whatever it be, I was sure it had to be me as the facilitator who had to do something to help them reduce their anxiety. I knew they were helpless enough to even deem it possible to be able to lower their affective barriers. While there is some amount of anxiety associated naturally with a learning context, it may be alarmingly aggravated or ameliorated by teachers' 
attitude. Loomax and Moosavi (1998) as well as Young (1991) found humour in the learning environment as an extremely effective tool to building up low-anxiety classroom. Chiasson (2003) emphasizes the importance of creating a positive atmosphere for learning. According to him, it is possible to reduce anxiety with the help of humour which can create a positive environment in a classroom and can improve learning.

In my experiments with my students, I started with humour. A strict classroom context, I believe, is the biggest tragedy that can happen to learning. The use of humour, something funny, a joke at times, happen to ease the learning environ, thus, facilitating learning. I remember one class in particular. I was teaching them Dangling Modifiers. Examples like, 'Having finished the book, the lights were switched off' could not strike the chord well with the students. Their faces seemed to tell me they were bored by the futility of this exercise. Finally, I came up with a funny example:

Jumping out of the bag, Ram caught the cat.

And this time it worked. There was not only a response but quite an animated discussion. In ten minutes, my job was done which I was struggling to accomplish for the last forty minutes. Humour is the best remedy to reduce all affective barriers, and I was convinced of its wonderful effect.

Horwitz (1986) mentions fear of negative evaluation as one of the components of anxiety, and more than half of my language class was anxious precisely due to this. After the ice was really broken, my students would come up to me in my chamber to share their horrible experiences with language teachers at the school. One student from Bihar (a majorly Hindi speaking state) had an interesting story to tell:

"I was considered a fairly good student by all my teachers but the language teacher did not let go of any opportunity to put me down. I used to pronounce waz as wa:s then, she would get mad at me for this and one day she said, "I will break a va:z (vase) on your head if you do not pronounce it waz." And she actually raised the wooden duster making a gesture to throw it at me. I changed my school.

A female student shared her experience of how her male teacher would pinch her in the bottom for her errors. She became so scared she would feign sickness to avoid his class. 
It is important to help students keep up their confidence as it is the best sedative for anxiety. The FLCAS (Foreign Language Classroom Anxiety Scale) developed by Horwitz, Horwitz and Cope (1986) focus, besides other aspects, on the learner's self-perception in statements like:

I feel more tense and nervous in my language class than in my other classes. 2. I keep thinking that the other students are better at languages than I am. 5. I can feel my heart pounding when I'm going to be called on in language class. (pp. 112-15)

Most of the researchers working with FLCAS have found higher positive response to these statements. Since my language class is a mix of students ranging from English medium schools to students from good, urban Hindi medium schools to those from rural Hindi medium schools who have but little exposure to English, there is a vast disparity among their proficiency levels. Learners from English medium background can be classified under two categories:

1. Those who have good class room exposure to the language

2. Those who have good social/home exposure to the target language

In the first category are students who come from completely Hindi speaking families and they depend on the classroom for whatever exposure they have to English. The second category comprises of students whose parents speak English in their daily life in this sense English is literally their mother tongue. Each of these four groups (the Rural Hindi group /the Urban Hindi group/ Classroom Exposure group and Classroom \& Social Exposure group; $\mathrm{RH} / \mathrm{UH} / \mathrm{CE} / \mathrm{CSE}$ ) has their different baggage that they bring into the classroom. The English teacher's task becomes naturally uphill when she has to facilitate learning among such a motley group at one time. In my early years, I made the mistake of making each of these groups exchange their class work for peer evaluation. But soon I realized this was playing havoc. On one hand the privileged CE and CSE groups were becoming bossy, and on the other hand, the RH and the UH groups were losing confidence (whatever they had). I, then, started thinking of ways to boost the confidence of the latter. While teaching grammar I would say: Any Hindi medium student, please tell us the rules.

And then I would say: "CBSE/ISC (Mostly CE and CSE group) students give an example." Initially the RH/UH groups were hesitant and many a times they mentioned the rules in a mix of $\mathrm{L}_{2}+\mathrm{L}_{1}$ (Hindi \& English). But gradually I saw my trick catching up; RH/UH groups had 
started to gain confidence that only they know the rules. They were proud that even the teacher confirms the facts from them before moving ahead. Those of them that were not so well-versed started coming to class fully prepared before hand so that they could steal the show from their peers. And those that knew the rules well but could not apply them so well started practising their grammar. More than half of my job was done when their confidence level increased. Maintaining a positive competitive atmosphere in the class is absolutely important for learning.

Another successful experiment that I have been using with my students is asking them to narrate the plot of the latest movie they watched. In my early years I used to get upset when they did not remember skills that they had learnt in their last class. I used to then ask them: "What was the last movie you saw?" They always answered very confidently. I used to then, rebuke them saying "Why don't you forget your movies? Why do you have to forget your lessons only?" But gradually I realized if it was their weakness I could well utilize it in my language class, making it their strength. I started chatting them up and in a couple of minutes I would come up with: "Which movie did you last see?" And then my next trap would be: "Must be a good one. Has good reviews. What is the story like?" Since it is an informal chat, most of the students do not even realize this is their test. Completely unaware of my implications, they excitedly narrate the plot. So high is their enthusiasm that each tries to shut the other up. I get a good communicative class where anxiety does not find room. An example:

$\mathrm{X}$ : The movie was a murder mystery.

Me: Okay! So it is a murder mystery.

Y: Don't say the mystery.

Me: Yes, please, don't unravel the mystery.

$\mathrm{X}$ : Huh! Nope! The hero was suspected of murder.

Me: Really! The hero is suspected of murder.

$\mathrm{X}$ : Yes, but actually some one other person does the murder.

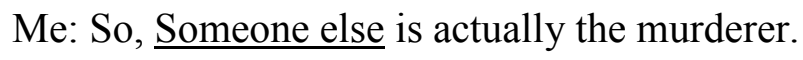

$\mathrm{X}$ : How he was caught, is the story.

Me: The story is about how they catch him.

Thus, I keep correcting their errors through repetition but while not many of the listeners realize my trick, even the speaker takes it as my enthusiasm, thus moving ahead effortlessly 
and with absolute confidence. It is only when all of them have given their inputs that I tell them: "So, you know how good you are at narration! Now let us do some drill." With renewed enthusiasm they participate knowing full well they have a friend in me, not a poking friend but a patient counselor who would come to their rescue as and when they so desire.

These students of mine have been my teachers. From their stories, I have learnt to maintain a positive environment. Over the years, I have learnt to be flexible and permissive to errors and repeat the same sentence using the correct syntax/ grammar/ vocabulary/ pronunciation, instead of overtly correcting them. Students are picking up fast and most importantly, they are not afraid of making mistakes as they do not fear evaluation knowing full well it is not going to be negative even if they make errors. Our Dean of the Faculty of Engineering and Technology tells me that a result analysis has shown maximum improvement in the language class. From a failure rate of $48 \%$ in 2002 we have achieved the rate of $6 \%$ this year. I target at $100 \%$ pass soon, and the way my experiments are breeding results, I am sure I'll have achieved that by the end of the next year. The credit of course, goes to all my students.

\section{Note}

There are many languages included in the Indian constitution but Hindi happens to be the most widely used language. There is a clear cut linguistic division between North Indian and South Indian states with Aryan group of languages being practiced in the North and those of Dravidian group being used in the South. However, Rajasthan, Bihar and U.P. in the North (not to mention Madhya Pradesh in the central India) have Hindi as their lingua franca. Uttar Pradesh is the most populous state easily outnumbers Hindi-users elsewhere. 


\section{References}

Arnold, J. (2000). Seeing through listening comprehension exam anxiety. TESOL Quarterly, 34, 784.

Hall, D.A. (2003). How to reduce students' anxiety to learn English in Taiwan? retrieved from $<$ it.snhu.edu/Su_Sierra/how\%20to\%20reduce\%20student's\%20anxiety.doc $>$

Chiasson, P.E. (2003). Using Humour in the Second Language Classroom. The Internet TESL Journal. Retrieved from $<$ http://iteslj.org/Techniques/Chiasson-Humour.html $>12$ September2009.

Daly, J. A. \& Miller, M. D. (1975). The empirical development of an instrument to measure writing apprehension. Research in the Teaching of English, 9, 242-249.

Ellis, R. (1994). Second Language Acquisition. NY: Oxford University Press.

Horwitz, E. (1986). Preliminary evidence for the reliability and validity of a foreign language anxiety scale. TESOL Quarterly, 20, 559-564.

Horwitz, E.K., Horwitz, M.B. \& Cope, J. (1986). Foreign language classroom anxiety. Modern Language Journal, 70(2), 125-132.

Krashen, S. D. (1981). Second Language Acquisition and Second Language Learning. CA: Pergamon Press.

Loomax, R. G., Moosavi, S. A. (1998). Using Humor to Teach Statistics; Must they be Orthogonal? Paper presented at the annual meeting of the American Educational Research Association, San Diego, April $17^{\text {th }}$, 1998. Qtd. in Chiasson Retrieved from < http://iteslj.org/Techniques/Chiasson-Humour.html >

MacIntyre, P. D., \& Gardner, R. C. (1989). Anxiety and second language learning: toward a theoretical clarification. Language Learning, 32, 251-275.

MacIntyre, P. D., \& Gardner, R. C. (1991). Methods and results in the study of foreign language anxiety: a review of the literature. Language Learning, 41(1), 283-305.

MacIntyre, P.D. (1995). How does anxiety affect second language learning? A reply to Sparks and Ganshow. The Modern Language Journal, 79(1), 90-99.

Price, M.L. (1991). The subjective experiences of foreign language anxiety: interviews with anxious students. In E.K. Horwitz \& D.J. Young (Eds.). Language Anxiety: From Theory and Research to Classroom Implications (pp. 101-108). Englewood Cliffs, NJ: Prentice Hall.

Scovel, T. (1991). The Effect of Affect on Foreign Language Learning: A Review of the Anxiety Research. In E.K. Horwitz \& D.J. Young (Eds.). Language Anxiety (pp. 101-108). Englewood Cliffs, NJ: Prentice Hall.

Sparks, R. L., \& Ganschow, L. (1995). A strong inference approach to causal factors in foreign language learning: a response to Mac Intyre. The Modern Language Journal, 79(ii), 235-244.

Sparks, R.L. \& Ganschow, L. (1991). Foreign language learning differences: affective or native language aptitude differences? Modern Language Journal, 75, 3-16.

Young, D.J. (1991). Creating a low-anxiety classroom environment: what does the language anxiety research suggest? Modern Language Journal, 75(4), 426-437. 